\title{
Recent Development and Advancement of Regenerative Braking in Electric Bike
}

\author{
Rohit Pandey
}

Assistant Professor, Mechanical Engineering Department, Amity University Madhya Pradesh, Gwalior M.P.-474005, India.

To Cite this Article

Rohit Pandey, "Recent Development and Advancement of Regenerative Braking in Electric Bike", International Journal for Modern Trends in Science and Technology, Vol. 06, Issue 06, June 2020, pp.:06-09; https://doi.org/10.46501/IJMTST060602

\section{Article Info}

Received on 26-April-2020, Revised on 22-May-2020, Accepted on 25-May-2020, Published on 28-May-2020.

\section{ABSTRACT}

Regenerative Braking System is the latest frontier of research and study in electric vehicles. Big firms are investing a lot to incorporate this system in vehicles. We through our project have tried to broaden the area of study and implementation of Regenerative Braking system even in Electric Bikes. Regenerative Braking system has been incorporated in many four-wheelers but its presence in the zone of two-wheelers is still untouched, so we decided to make a move to contribute our learning and skills to explore in this untouched sector of two-wheelers. We have manufactured a model to test Regenerative Braking system in an electric bike and have made an attempt to prove it worth through our efforts.

KEYWORDS: Non-Conventional Transportation, Regenerative Braking, Electric Bike, Waste Energy Regeneration, Efficiency.

Copyright (C) 2014-2020 International Journal for Modern Trends in Science and Technology

DOI: https://doi.org/10.46501/IJMTST060602

\section{INTRODUCTION}

The concept of Regenerative Braking is a result of outbreak of new innovations in the field of energy, especially dealing with transformation of waste energy into a productive one. The concept itself reveals some information about the Regenerative Braking through its literal meaning and senses. As per the universal law of Conservation of Energy, energy can neither be created nor can be destroyed. The same is in the case of Regenerative Braking where one form of energy (i.e. energy being wasted) is transformed into another form of energy (i.e. useful form of energy). In the case of conventional braking when brakes are applied they tend to retard or stop the motion of the vehicle by converting the kinetic energy of the wheels into heat energy and further the heat produced is dissipated in the surrounding and this is how the law of Conservation of Energy comes into play. Regenerative Braking has an extra advantage over the conventional braking system as it regenerates energy (i.e. electrical energy) during the conversion of kinetic energy into heat energy while braking in conventional braking systems with the use of some mechanical arrangements and store them so generated electrical energy into batteries for further use. The rate at which our natural fuel stocks are depleting, and the rapid increase of adverse effects of emission worldwide, is been an alarming situation that if it's not dealt at the earliest with proper planning may even result into end of mankind on this mother earth. Every other concept dealing with usage of resources that are non-conventional and reproducing energy from those forms which are liberated as waste is commendable. Regenerative Braking is one such 
emerging concept that extends the scope of energy conservation to a new and unexplored platform. This concept of Regenerative Braking has come into practical application a few years back in four-wheelers (viz. Maruti Ciaz) and is been a great success, this lead us to thought about its applicative extension further in two-wheelers. India is considered to be one of the largest producer as well as consumer of automobiles. Stats have shown that India is largely a market predominant of consumers of two-wheelers, and the increasing inclination of consumers towards Hybrid or Battery equipped vehicles further extends a great platform and opportunity to incorporate new ideas to increase its market capitalization also taken into account about the increasing pollution and effects due to greenhouse gases. 2 with this paper aim to incorporate Regenerative Braking in two-wheelers especially on those working on battery (i.e. Battery Electric Vehicle or BEV). Our attempt is mainly focused on two-wheelers as it comes under a good economical price and targets a wide population of Indian consumers. Though its application is not only limited to Electric Vehicles and can easily be extended to conventional gasoline vehicles and can even be incorporated in the upcoming Ethanol vehicles with few extra arrangements of motor, dynamos, some mechanical mechanism and miscellaneous equipment that comes under a reasonable price.

\section{WORKING PRINCIPAL OF REGENERATIVE SYSTEM}

In the case of conventional braking systems brake pads are used for stopping or retarding the motion of the vehicles and as a result of direct contact produces friction when the brake pads got intact with the brake rotors. In addition to that as the wheel starts stopping it even produces friction with the road surface. This friction is a resultant that causes heating effect in the conventional braking systems, and this is how the kinetic energy of the moving vehicle gets transformed into heat energy during stopping or retardation. On the other side in the case of Regenerative Braking, a dynamo of specifications suitable as per the vehicle's class is mounted on the brake callipers and these dynamos come into real action during braking. As the drivers pull's the brake lever, these brake callipers mounted with dynamos on them gets pressed against with the wheel, thus resulting into slowing down the vehicle and ultimately stopping the vehicle. As the dynamos gets into direct contact with the moving wheel of the vehicle, it starts rotating on a fixed axis under the action of magnetic field and hence starts acting as an electric generator producing electricity which then is fed in a battery. Experimental recordings had brought up a miraculous thing about regenerative braking on the screen that it (i.e. Regenerative Braking) may be able to restore half of the energy that is being wasted as heat during braking and put it back into work, and hence results into reduced fuel consumptions even up to $20 \%-25 \%$.

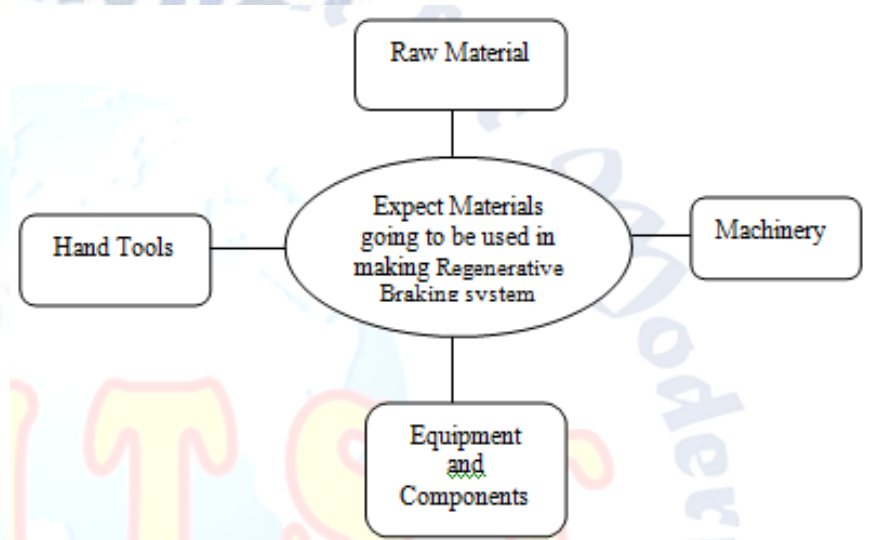

Figure 1: Cluster Layout of Expected Materials required in making Regenerative braking system.

\section{ADVANTAGES OF REGENERATIVE BRAKING}

Regenerative Braking system is the modern day technique of breaking that comes with its own set of advantages and limitations that must be taken into account for better results. Some of the advantages of regenerative system are discussed later in this section: 3 a) Maintenance cost associated with regenerative braking system is very less when compared with the conventional braking systems as it does not requires changing brake shoes periodically. b) Deploying regenerative braking system even gives us an extra edge to increase the capacity of the system (i.e. vehicle's capacity) in terms of its speed and load carrying capacity. c) Running cost associated with the vehicle is reduced by a noticeable amount as a part of energy that is earlier being wasted is now continuously being supplied back to the batteries. d) In regenerative braking technology a negligible amount of heat is produced in comparison to the mechanical braking systems at brake shoes which lead to damage the brakes shoes or pads and ultimately leading to failure of brakes.

\section{LIMITATIONS OF REGENERATIVE BRAKING}

Regenerative Braking system has a limitation that it fails to hold the vehicle at uphill or downhill 
after coming to rest and this is why it is always incorporated in the vehicle along with a mechanical braking. We in our project have incorporated the Regenerative Braking System in two-wheelers like electric bike and hence it becomes obvious to know few things about what the electric bike is, how it works, which fuel it consumes, and many more things about it. A detailed analysis of electric bike is done in this text below. Electric Bike A bike which runs on batteries and electric motor is known as electric bike or commonly referred as e-bike, and these bikes are propelled by the batteries. The batteries and electric motors are capable of providing instant torque to the bike which results into smooth and strong acceleration. These Electric bikes use rechargeable batteries of different specifications based on their built and cost. Electric bikes are very efficient if compared to bikes running on gasoline. Electric bikes are on average three times more efficient also the cost of maintenance and running in comparison to conventional bikes using gasoline is very less. A comparison on the two is described below. 4 As each and every different kind of vehicles is having their own advantages and disadvantages associated with them. Various advantages of electric bike over bike running on Fossil fuels are:

(a) Electric bikes do not emit harmful gases such as Carbon Dioxide, Carbon Mono oxide, shoots, oxides of nitrogen, oxides of sulphur etc. which continuously pollutes the environment and are even hazardous to the people.

(b) Power to weight ratio can be increased with the use of electric motors of varying specifications as per the requirement.

(c) Electric motors provide constant torque which leads to very high acceleration performance of the electric

vehicle compared to the bikes running on internal combustion engine.

(d) Motor to wheel technique can also be used in electric vehicles due to which available power can be increased. With no differential fitted on the axle electric vehicles leads to low drive train rotational inertia.

Also with this technique all the wheel can be used for acceleration and similarly for braking thus leading to very less traction and frictional losses. (e) Electric bikes are very efficient in converting the battery power to propulsion whereas internal combustion engines are very inefficient in consuming or utilizing the full energy of fuel to drive the bike. Typically, petrol bikes are five percent (5\%) efficient whereas diesel bikes are twenty percent $(20 \%)$ while the electric vehicles are eighty percent $(80 \%)$ efficient.

(f) Noise pollution from the electric vehicles is negligible if compared with bikes running on internal combustion engine.

\section{MATERIALS AND METHODS}

A. Materials required

The expected materials that are going to be used in the making of the regenerative braking system are many to count on fingers ranging from machines, raw materials, hand tools, to equipment's and etc. As it is tough to mention and discuss about all the material required for the manufacturing of braking mechanism at this stage so in this section of the draft we will encounter and discuss about every possible input that have been used to build the regenerative braking mechanism. This part of the draft will be focusing on methodology of making the braking system along with its possible explanations to enable us understand the necessity of these braking system in our modern day approach of manufacturing vehicles.

\section{B. Raw Materials}

There are many items that are used as raw material for manufacturing the Regenerative Braking system some of them are discussed below. Steel Tubes The raw materials that will be consumed during the making of Regenerative Braking system are prominently Steel Tubes for the making of structural cage that will act as the foundation or base to support and mount other components over it. The choice of the steel tubes is a tedious job as we need to select the best quality material and economical in such a way that the strength of the structural foundation must not be compromised and weight of the whole unit must be in the considerable range. This leads to the choice hollow steel tubes rather than the solid one because when compared on the parameter of strength the hollow tubes have greater strength in comparison to the solid tubes and their weight is also lesser than the solid steel tubes. As it was all set to go for hollow steel tubes as our primary raw material for the roll cage then we witnessed the problem of selection of circular hollow tubes or the rectangular hollow tubes for the manufacturing of braking system. We then conducted some tests on sample specimen of both the types of hollow tubes and in our result concluded on the fact that when compared on the scale of strength the circular tubes have an extra edge over the rectangular one, but on second 
thought we concluded that welding in rectangular tubes is quite easier than the circular one as they have their meeting edges at $90^{\circ}$ which are very helpful for a firm and solid grip during welding. So we decided to build the structural truss of the braking system from the rectangular tubes.

\section{Brake Mechanism and Accessories}

Although the brake mechanism that is used in this system of Regenerative Braking is customized one and hence cannot be treated as a complete raw material but as we get it directly from an automotive workshop it is kept in the category of raw material. The other different accessories that are used as raw materials are: a) Electric wires b) Brake wires and cables c) Nut and Bolts d) Circular clampers e) Rivets and Screws f) Shaft (for power transmission) g) Abrasive Washers h) Electricity conductive Tapes.

\section{Equipment and Components}

There are few components that cannot be made in a workshop at very small level and so these equipment's or components are directly taken into use considering their specifications as per our requirement. We have also used four such components to complete the project and make it a worth, and the components are: a) Motor b) Battery c) Accelerator d) Dynamos These components are discussed it details later in this section.

\section{CONCLUSION}

Manufacturing industries are now the biggest sectors of world economy and are the life line of mankind. Automobile manufacturing is one such daughter branch of this sector, with the increasing demands and rising living standards of society automobile manufacturing industry is at its highest and is even been predicted that will grow with time. Especially considering the Indian market and its consumers it is quite easy to conclude that more than $50 \%$ of the total consumer in the society is dependent on economic mode of transportation system. Two-wheelers are the answer to their demands. Indian market of two wheelers is growing rapidly as the consumers are getting aware about issues like pollution and green house effects are tremendously switching to eco-friendly alternatives and in economic range. E-bikes are the new trend among the Indian automobile consumers. These stats acted as the genesis of idea to pursue project on Regenerative Braking.

\section{ACKNOWLEDGEMENT}

Author would like to thank Amity University for giving such a wonderful research facility to do this research work and giving valuable Experimental facility to complete this research work and also thank to my Ph.D Supervisor to support and guide me for this research paper work.

\section{REFERENCES}

[1] Guodong Yin and Xian Jian Jin, October, 2013, Cooperative Control of Regenerative Braking and Antilock Braking for a Hybrid Electric Vehicle".

[2] Guido Wager, November 17, 2017, Jonathan Whale and Thomas Braunl, "Performance Evaluation of Regenerative Braking Systems".

[3] Khelan Chaudhari, Amogh Joshi, Ranjit Kunte,2011 "Design \& Development of roll cage for an all-terrain vehicle".

[4] Willett Kempton, 2013 "Electric vehicles as a new power source for electric utilities", Elsevier, Vol. 2, Issue 03.

[5] Introduction to Basic Manufacturing Process and Workshop Technology, "Rajendra Singh" 2001. Vol. 3, Issue 04.

[6] Workshop Technology, "S.K. Hajra Chaudhary, Nirjhar Roy", Published 2007.

[7] Automobile Engineering, "Dr. Kripal Singh", Published 2004.

[8] A. Pina, P. Baptista, C. Silva, and P. Ferro, 2014."Energy reduction potential from the shift to electric vehicles: The Flores island case study," Energy Policy, vol. 67, no. 0, pp. $37-47$.

[9] C. Ziogou, D. Ipsakis, P. Seferlis, S. Bezergianni, S. Papadopoulou, and S. Voutetakis, 2013 "Optimal production of renewable hydrogen based on an efficient energy management strategy," Energy, vol. 55, no. 0, pp. 58 $-67$.

[10] Melody L. Baglione, 2007. "Development of system analysis methodologies and tools for modeling and optimizing vehicle system efficiency," Ph.D. dissertation, University of Michigan.

[11] Ali Emadi, 2005. Energy - Efficient Electric Motors. New York: Marcel Dekker.

[12] P. Sharma and T. Bhatti, 2010 "A review on electrochemical double-layer capacitors," Energy Conversion and Management, vol. 51, no. 12, pp. $2901-2912$.

[13] L. Sun and N. Zhang, 2015 "Design, implementation and characterization of a novel bi-directional energy conversion system" Applied Energy, no. 0, pp. -, 2014.Energy Reviews, vol. 41 , no. 0 , pp. $225-236$.

[14] P. J. Hall and E. J. Bain, 2017 "Energy-storage technologies and electricity.

[15] B. H. Kim, O. J. Kwon, J. S. Song, S. H. Cheon, and B. S. $\mathrm{Oh}, 2014$. "The characteristics of regenerative energy for pemfc hybrid system with additional generator," International Journal of Hydrogen Energy, vol. 39, no. 19, pp. $10208-10215$.

[16] Z. Kohavi and N. Jha, 2010. Switching and Finite Automata Theory. Cambridge University Press. 